\title{
Stigma of Mental Illnesses as Perceived by North Korean Defectors Living in South Korea
}

\author{
Ji-Hoon Ahn ${ }^{1}$, Won-Hyoung Kim ${ }^{1} \bowtie$, Hye-Jin $\mathrm{Choi}^{2}$, Jin-Yong Jeon ${ }^{3}$, In-Gyu Song ${ }^{4}$, and Jae-Nam Bae ${ }^{1}$ \\ ${ }^{1}$ Department of Psychiatry, Inha University Hospital, Incheon, Republic of Korea \\ ${ }^{2}$ Department of Psychiatry, Gyeonggi Provincial Medical Center Suwon Hospital, Suwon, Republic of Korea \\ ${ }^{3}$ Department of Psychiatry, Settlement Support Center for North Korean Refugees, Anseong, Republic of Korea \\ ${ }^{4}$ Graduate School of Public Health Seoul National University, Seoul, Republic of Korea
}

Objective This study aims to provide the information of the stigmas of mental illness such as psychosis, alcoholism, attempt suicide, and depression among North Korean defectors.

Methods We examined stigma for the mental illnesses of 639 North Korean defectors aged 19 to 65 years who live in the Settlement Support Center for North Korean Refugees. The stigmas of mental illnesses were assessed using the Perceived Devaluation-Discrimination Scale We directly compared the stigma level between North Korean defectors and the general population of South Korea.

Results North Korean defectors had higher perceived stigmas of psychosis and alcoholism and lower perceived stigmas of depression than South Koreans. Perceived stigma associated with attempted suicide was similar for North Korean defectors and South Koreans. Only marital status in sociodemographic variables had associations with higher perceived stigma of psychosis, alcoholism, and depression in the North Korean defectors. North Korean defectors, who spent more than one year in transit country, had associations with lower perceived stigma of psychosis and alcoholism. North Korean defectors, who had the experience of compulsory repatriation to North Korea or North Korean family in South Korea, had an association with higher perceived stigma of depression.

Conclusion North Korean defectors had higher perceived stigmas of psychosis and alcoholism and lower perceived stigmas of depression than South Koreans. Further studies are needed to document serial changes in stigmas for mental illnesses associated with the receipt of education at the Settlement Support Center for North Korean defectors.

Psychiatry Investig 2015;12(1):9-15

Key Words Stigma, North Korean defectors, Mental illnesses.

\section{INTRODUCTION}

The closed system of the Democratic People's Republic of Korea (North Korea) prevents assessment of mental illnesses, such as, prevalences, risk factors, treatments, and prejudice. Furthermore, there may be a huge gap between what North Korea officially discloses and the real situation. Therefore, we considered that studies of North Korean defectors could better reveal the statuses of mental illnesses.

Since 1994, the number of North Korean defectors has in-

Received: December 23, 2013 Revised: February 4, 2014

Accepted: March 27, 2014 Available online: October 1, 2014

$\triangle$ Correspondence: Won-Hyoung Kim, MD

Department and Research Institute of Psychiatry, Inha University College of Medicine, 27 Inhang-ro, Jung-gu, Incheon 400-711, Republic of Korea

Tel: +82-32-890-3540, Fax: +82-32-890-3558, E-mail: ckgodman@hanmail.net

(a) This is an Open Access article distributed under the terms of the Creative Commons Attribution Non-Commercial License (http://creativecommons.org/licenses/by$\mathrm{nc} / 3.0$ ) which permits unrestricted non-commercial use, distribution, and reproduction in any medium, provided the original work is properly cited. creased significantly due to political, economic, and social difficulties. It was reported at the end of 2013 that North Korean defectors in South Korea numbered more than 26,000. ${ }^{1}$ In response, the government of the Republic of Korea (South Korea) has helped resettle North Korean by providing support for living, housing, education, employment and others. ${ }^{2}$

Mental health is one of the most significant factors in the contest of the successful adaption to a new environment., ${ }^{3,4}$ In 2005, Medecins Sans Frontieres (South Korea) reported that $37.6 \%$ of North Korean defectors experienced psychological problems. ${ }^{5}$ And according to another study, more than $40 \%$ of North Korean defectors had somatization and/or depression. Yet, $83 \%$ of those surveyed answered had not received any forms of psychiatric help. ${ }^{6}$

In fact, South Koreans use mental health service less than Nigerians, South Africans, Americans, Latinos, Australians, and Israelis, ${ }^{7}$ and it has been reported that in South Korea, culture-influenced personal beliefs (knowledge about mental ill- 
ness and stigma) play a substantial role in shaping individuals' attitudes toward mental health service. ${ }^{8}$ As the stigma of mental illness substantially influences the attitudes of South Koreans and reduce the utilization of mental health services, we considered that the same to that of general population and North Korean defectors. ${ }^{7}$

Despite of much research on the mental health of North Korean defectors, few studies have addressed the stigmas of mental illnesses in North Korean defectors. This study addresses the stigmas of mental illness such as those concerning psychosis, alcoholism, attempted suicide, and depression among North Korean defectors. In addition, it examines associations between stigmas and sociodemographic characteristics of North Korean defectors.

\section{METHODS}

The stigmas of mental illnesses were examined in 639 North Korean defectors aged 19 to 65 residing in a Settlement Support Center for North Korean Refugees from June 2012 to February 2013. All 639 had been in South Korea for less than 3 months. We excluded the illiterate subjects and the self-surrendered subjects who had been lived in more than 1 year in South Korea. Of these 639 subjects, 545 completed the Perceived Devaluation-Discrimination scale (PDD), ${ }^{9-12}$ the Korean version of Psychiatric Diagnostic Screening Questionnaire (K-PDSQ), ${ }^{13,14}$ and sociodemographic questionnaires an overall response rate of $85.3 \%$. Two physicians with more than 6 months of experience of treating North Korean defectors performed the interviews. Before interviews, physicians explained only the symptoms of depression, because of subject unfamiliarity with the term. The study was approved by the institutional review board of Inha University College of Medicine and by the Settlement Support Center for North Korean Refugees. All study subjects were informed of the purpose and the methods of the study and provided written informed consent.

\section{Perceived Devaluation-Discrimination Scale}

The stigmas of mental illnesses were assessed using a 12item scale adapted from the Perceived Devaluation-Discrimination Scale, ${ }^{10-12}$ which was translated and validated by Lee. ${ }^{9}$ The scale measures the severity to which participants believe that a person with a mental illness will be stigmatized if their disorder were known. ${ }^{12,15,16}$ Individual responses to questions were scored using a six-point Likert scale, as follows: 1) Strongly agree, 2) Agree, 3) Somewhat agree, 4) Somewhat disagree, 5) Disagree, and 6) Strongly disagree. Summed (total) individual scores approximated to a normal distribution, where a higher total score indicates greater perceived stigma.

The PDD was subdivided into four scales, which assessed perceived stigma regarding four mental illnesses, namely, psychosis, alcoholism, attempted suicide, and depression. Some words in the psychosis questionnaire, such as, "mental patients", "mental disorder", and "mental hospital" were changed to "patients with psychosis", "psychosis", and "a hospital to treat psychosis." Questions were changed in the same way in the other three PDDs. $^{17}$

The North Korean defectors answered all four types of PDD. However, 3,055 South Koreans were randomly allocated into four groups, each group answering only one type among four types of PDD. ${ }^{17}$ Cronbach's alpha coefficient for psychosis, alcoholism, attempted suicide, and depression PDDs were 0.828, $0.782,0.832$, and 0.756 , respectively.

\section{The Korean Version of Psychiatric Diagnostic Screening Questionnaire}

Psychiatric Diagnostic Screening Questionnaire (PDSQ), ${ }^{13}$ a useful self-reporting test with 125 questions. Kwak et al. reported an PDSQ optimal cutoff scores for ten types of psychiatric status, that is, major depressive disorder, posttraumatic stress disorder, obsessive-compulsive disorder, panic disorder, alcohol-related problems, generalized anxiety disorder, hypochondriasis, and social phobia among the general population of South Korea. ${ }^{14}$ We defined mental illness based on the presence of one of ten types.

\section{Sociodemographic and clinical variables}

We assessed sociodemographic variables, which included age, gender, level of education (years), and marital status (married or previously married/never married). Date of escape from North Korea, number of days spent in transit countries, experience of compulsory repatriation to North Korea, and number of family members in South Korea were documented.

\section{The 2011 Epidemiological Survey of Mental Disorders in Korea}

To estimate the prevalence and correlates of mental disorders in South Korea, a nationwide epidemiological study was conducted from July 2011 to October $2011 .^{19}$ The Korean version of the WHO-Composite International Diagnostic Interview (K-CIDI) was used as an assessment tool, and the Perceived Devaluation-Discrimination scale was also used to measure the stigma associated with mental illnesses. ${ }^{17}$

The North Korean defectors answered all four PDDs, but 3,055 South Koreans were randomly allocated to four groups, and each group answered only one of the four PDDs. ${ }^{17} \mathrm{We}$ directly compared the stigma level between North Korean defectors and the general population of South Korea as the same PDD scale was applied to the both groups. 


\section{Statistical analysis}

The independent t-test was used for bivariate analysis using stigma levels for psychosis, alcoholism, attempted suicide, and depression among North Korean defectors and the general population of South Korea. In addition, linear regression was used to examine associations between demographic predictors/general characteristics/mental illness and stigma in North Korean defectors. The demographic predictors analyzed were age (<35/35-49/50-64), gender (men/women), level of education $(0-6 / 7-12 />12)$, and marital status (married or previously married/never married). Point estimates from linear regression models are presented after adjusting simultaneously for demographic covariates, namely, age, gender, the level of education, and marital status.

Missing data was excluded from the analyses. The analysis was performed using SPSS 12.0 (SPSS Inc., Chicago, IL, USA), and statistical significance was accepted for $\mathrm{p}$ values $<0.05$.

\section{RESULTS}

\section{Demographic characteristics of the North Korean defectors}

The mean overall age of the 545 defectors was 35.5 years (SD 10.6), and for male and female defectors mean ages were 32.9 years (SD 11.9) and 36.3 years (SD 10.2), respectively. Female defectors accounted for $78.0 \%$ of the defectors, and $45.0 \%$ of all defectors were less than 35 years old. Nearly $80 \%$ (79.4\%) had attended secondary school, $49.5 \%$ were married, $23.5 \%$ were previously married, and $27.0 \%$ have never been married
(Table 1).

\section{Perceived Devaluation-Discrimination Scale}

Mean PDD scale scores for psychosis, alcoholism, attempted suicide, and depression were $49.19(\mathrm{SD}=9.44), 46.35(\mathrm{SD}=8.69)$, $38.53(\mathrm{SD}=9.49)$, and $35.64(\mathrm{SD}=9.30)$. North Korean defectors had a higher score for psychosis than the South Korea population (49.19 vs. 41.05, p<0.001). Also defectors had a higher alcoholism score than South Koreans ( 46.35 vs. 42.85, p<0.001). However, North Korean defectors had a lower PDD score of depression (35.64 vs. 37.00, $\mathrm{p}=0.007$ ), and a near identical PDD score of attempted suicide (38.53 vs. 38.81, $\mathrm{p}=0.575$ ) (Figure 1).

\section{Relationships between demographic characteristics and perceived stigmas of mental illnesses}

Table 2 presents associations between perceived stigmas of psychosis, alcoholism, attempted suicide, and depression and sociodemographic characteristics in defectors. Perceived stigmas of psychosis, alcoholism, and depression were significantly higher in defectors who were married or previously been married than in those that had never been married $(p<0.05)$. Demographic characteristics were not found to be associated with perceived stigma of attempted suicide.

\section{Relationships between general characteristics, mental illnesses, and the stigmas of mental illnesses}

More than three-quarters (76.3\%) of North Korean defectors were diagnosed to have a mental illnesses by K-PDSQ. The presence of a mental illness was not found to be associated

Table 1. Sociodemographic characteristics of the subjects who answered on the stigma of each mental illness

\begin{tabular}{|c|c|c|c|c|c|}
\hline & \multirow{2}{*}{ North Korean defectors } & \multicolumn{4}{|c|}{ South Korean* } \\
\hline & & Psychosis $^{\dagger}$ & Alcoholism $^{\dagger}$ & Attempted suicide $^{\dagger}$ & Depression $^{\dagger}$ \\
\hline Number & 545 & 756 & 778 & 778 & 743 \\
\hline Gender (women, \%) & 78.0 & 58.3 & 62.6 & 62.5 & 62.3 \\
\hline \multicolumn{6}{|l|}{ Age } \\
\hline$<35(\%)$ & 45.0 & 21.4 & 21.9 & 20.8 & 22.1 \\
\hline $35-49(\%)$ & 44.8 & 34.0 & 29.7 & 31.2 & 30.3 \\
\hline $50-64(\%)$ & 10.2 & 26.3 & 28.1 & 29.2 & 27.2 \\
\hline$\geq 65(\%)$ & - & 18.3 & 20.3 & 18.8 & 20.5 \\
\hline \multicolumn{6}{|l|}{ Education } \\
\hline $0-6(\%)$ & 10.5 & 16.8 & 21.5 & 19.4 & 20.3 \\
\hline $7-12(\%)$ & 79.4 & 44.8 & 47.3 & 45.4 & 44.3 \\
\hline$>12(\%)$ & 10.1 & 38.4 & 31.2 & 35.2 & 35.4 \\
\hline \multicolumn{6}{|l|}{ Marital status } \\
\hline Married/previously married (\%) & 73.0 & 70.7 & 82.4 & 80.5 & 80.5 \\
\hline Never married (\%) & 27.0 & 29.3 & 17.6 & 19.5 & 19.5 \\
\hline
\end{tabular}

*the data was quoted from Choi's article, ${ }^{17}+$ South Koreans were randomly allocated to four groups by four types of PDD, such as psychosis, alcoholism, attempted suicide, and depression. PDD: Perceived Devaluation-Discrimination Scale 
with perceived stigmas of mental illnesses. Table 3 presents the effects by number of days spent in transit countries, compulsory repatriation, family in South Korea, and mental illness on the perceived stigmas of mental illnesses in defectors Those that spent more than one year in transit countries, had lower stigmas for psychosis and alcoholism. North Korean defectors that had experienced compulsory repatriation to North Korea or had one or more North Korean family members in South Korea had higher perceived stigma for depression. The presences of psychosis, alcoholism, and depression were not found to be associated with perceived stigmas of mental illnesses. No significant differences in the PDD scale for psychosis, alcoholism, and depression were observed between defectors with or

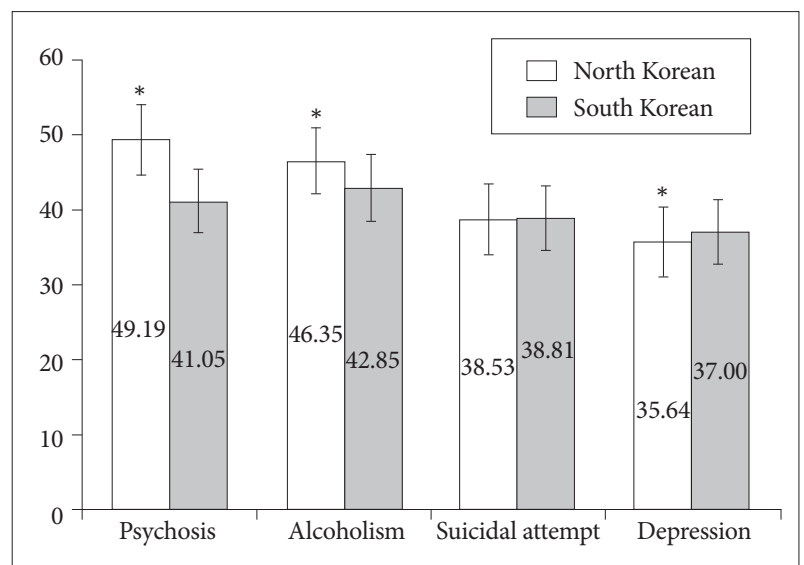

Figure 1. Comparison of the stigma on psychosis, alcoholism, attempted suicide, and depression between North Korean defectors and South Korean. Error bars represent 95\% confidence intervals. ${ }^{*}$ p-value $<0.05$. without each mental illness (Table 4).

\section{DISCUSSION}

This report documents for the first time stigmas of mental illnesses and associated factors held by North Korean defectors.

In this study, the North Korean defectors had higher perceived stigmas for psychosis and alcoholism than South Korean subjects. In North Korea, a psychiatric clinic is called 49th (pronounced Sahsip-gu-ho in Korean). Generally, North Koreans think that 49th patients suffer from severe hallucinations, delusions, or inappropriate affect. Furthermore, 49th is diagnosed as schizophrenia or a manic state by general physicians and after diagnosis individuals are isolated from society and sent to a 49th ward in secluded area. Most North Koreans have very negative images of $49 \mathrm{th}^{20}$ Alcoholism was rare in North Korea until the late 1990s because alcohol production and distribution were under government control. However, since the late 1990s, individuals have been allowed to produce alcoholic drinks at home, and alcoholism is encountered more often. ${ }^{20}$ Some studies have reported that the prevalence of alcoholism is high among North Korean defectors. ${ }^{21,22}$ Alcoholism can cause many problems, such as, divorce and family dysfunctionality, ${ }^{23}$ and this is likely to negatively affect North Korean stigma regarding alcoholism.

It was interesting to find that perceived stigma associated with attempted suicide was similar for defectors and South Koreans. Because in North Korea suicide is regarded as a treasonous act and the social classes of family members are degraded, it might be expected that the country's suicide rate

Table 2. Difference in effect of stigma of mental illness by sociodemographic variables in the North Korean defectors

\begin{tabular}{|c|c|c|c|c|c|c|c|c|}
\hline & \multicolumn{2}{|c|}{ Psychosis* } & \multicolumn{2}{|c|}{ Alcoholism* } & \multicolumn{2}{|c|}{ Attempted suicide* } & \multicolumn{2}{|c|}{ Depression* } \\
\hline & $\beta(\mathrm{SE})$ & $\mathrm{p}$-value & $\beta(\mathrm{SE})$ & $\mathrm{p}$-value & $\beta(\mathrm{SE})$ & $\mathrm{p}$-value & $\beta(\mathrm{SE})$ & $\mathrm{p}$-value \\
\hline \multicolumn{9}{|l|}{ Sex } \\
\hline Male & $0.53(1.03)$ & 0.606 & $-0.72(0.95)$ & 0.445 & $0.24(1.05)$ & 0.823 & $0.40(1.02)$ & 0.697 \\
\hline Female & 0.00 & & 0.00 & & 0.00 & & 0.00 & \\
\hline \multicolumn{9}{|l|}{ Age, years } \\
\hline $18-34$ & $0.15(1.42)$ & 0.916 & $-1.39(1.30)$ & 0.286 & $-2.25(1.45)$ & 0.121 & $-1.03(1.41)$ & 0.464 \\
\hline $35-49$ & $0.92(1.42)$ & 0.517 & $-1.01(1.30)$ & 0.437 & $-1.28(1.44)$ & 0.375 & $0.05(1.40)$ & 0.974 \\
\hline $50-64$ & 0.00 & & 0.00 & & 0.00 & & 0.00 & \\
\hline \multicolumn{9}{|l|}{ Education } \\
\hline $0-6$ & $-2.86(1.80)$ & 0.112 & $1.88(1.65)$ & 0.254 & $0.33(1.83)$ & 0.857 & $3.29(1.78)$ & 0.065 \\
\hline $7-12$ & $-0.07(1.34)$ & 0.958 & $1.59(1.23)$ & 0.196 & $-0.37(1.37)$ & 0.978 & $0.49(1.33)$ & 0.711 \\
\hline$>12$ & 0.00 & & 0.00 & & 0.00 & & 0.00 & \\
\hline \multicolumn{9}{|l|}{ Marital status } \\
\hline Married/previously married & $2.37(0.98)$ & 0.015 & $3.24(0.89)$ & $<0.001$ & $1.56(0.99)$ & 0.116 & $2.54(0.96)$ & 0.009 \\
\hline Never married & 0.00 & & 0.00 & & 0.00 & & 0.00 & \\
\hline
\end{tabular}

*adujsted for all demographic covariates simultaneously. SE: standard error 
Table 3. Differences in number and effect of stigma of mental illness by general characteristics and mental illness in the North Korean defectors

\begin{tabular}{|c|c|c|c|c|c|c|c|c|c|}
\hline & \multirow{2}{*}{$\begin{array}{c}\begin{array}{c}\text { North Korean } \\
\text { defectors }\end{array} \\
\mathrm{N}(\%)\end{array}$} & \multicolumn{2}{|c|}{ Psychosis* } & \multicolumn{2}{|c|}{ Alcoholism* } & \multicolumn{2}{|c|}{ Attempted suicide* } & \multicolumn{2}{|c|}{ Depression* } \\
\hline & & $\beta(\mathrm{SE})$ & p-value & $\beta(\mathrm{SE})$ & p-value & $\beta(\mathrm{SE})$ & p-value & $\beta(\mathrm{SE})$ & p-value \\
\hline \multicolumn{10}{|c|}{ Length of days in transit countries } \\
\hline$>1$ year & $351(64.4)$ & $-2.08(0.92)$ & 0.025 & $-1.88(0.85)$ & 0.027 & $-1.51(0.94)$ & 0.109 & $-0.57(0.92)$ & 0.534 \\
\hline$\leq 1$ year & $194(35.6)$ & 0.00 & & 0.00 & & 0.00 & & 0.00 & \\
\hline \multicolumn{10}{|c|}{ Compulsory repatriation } \\
\hline Yes & $127(23.3)$ & $-0.48(1.04)$ & 0.624 & $0.43(0.50)$ & 0.391 & $0.59(0.99)$ & 0.553 & $2.41(0.95)$ & 0.012 \\
\hline No & $418(76.7)$ & 0.00 & & 0.00 & & 0.00 & & 0.00 & \\
\hline \multicolumn{10}{|c|}{ Family in South Korea } \\
\hline Yes & $189(34.7)$ & $0.75(0.85)$ & 0.615 & $0.17(0.78)$ & 0.833 & $1.26(0.87)$ & 0.148 & $1.69(0.84)$ & 0.045 \\
\hline No & $356(65.3)$ & 0.00 & & 0.00 & & 0.00 & & 0.00 & \\
\hline \multicolumn{10}{|c|}{ Mental illnesses ${ }^{\dagger}$} \\
\hline Yes & $417(76.5)$ & $-0.28(0.23)$ & 0.226 & $-0.10(0.21)$ & 0.633 & $0.18(0.23)$ & 0.939 & $-0.10(0.23)$ & 0.673 \\
\hline No & $128(23.5)$ & 0.00 & & 0.00 & & 0.00 & & 0.00 & \\
\hline \multicolumn{10}{|l|}{ Psychosis $^{\dagger}$} \\
\hline Yes & $194(35.6)$ & $-0.01(0.21)$ & 0.959 & - & - & - & - & - & - \\
\hline No & $351(64.4)$ & 0.00 & & - & - & - & - & - & - \\
\hline \multicolumn{10}{|c|}{ Alcoholism $^{\dagger}$} \\
\hline Yes & $89(16.4)$ & - & - & $-0.42(0.26)$ & 0.114 & - & - & - & - \\
\hline No & $456(83.6)$ & - & - & 0.00 & & - & - & - & - \\
\hline \multicolumn{10}{|c|}{ Depression $^{\dagger}$} \\
\hline Yes & $88(16.2)$ & - & - & - & - & - & - & $-0.26(0.27)$ & 0.341 \\
\hline No & $457(83.8)$ & - & - & - & - & - & - & 0.00 & \\
\hline
\end{tabular}

*adujsted for all demographic covariates simultaneously, ${ }^{\dagger}$ mental illnesses, psychosis, alcoholism and depression were diagnosed according to Korean version of Psychiatric Diagnostic Screening Questionnaire. SE: standard error

Table 4. Effect of the presence of mental illnesses on perceived stigma

\begin{tabular}{|c|c|c|c|c|c|c|}
\hline \multirow{2}{*}{ Diagnosis } & \multicolumn{2}{|c|}{ North Korean defectors* } & \multirow{2}{*}{ p-value } & \multicolumn{2}{|c|}{ South Korean ${ }^{\dagger}$} & \multirow{2}{*}{ p-value } \\
\hline & $\mathrm{N}(\%)$ & Mean (SD) & & $\mathrm{N}(\%)$ & Mean (SD) & \\
\hline Psychosis & & & & & & 0.871 \\
\hline No & 350 & $49.25(9.74)$ & \multirow{2}{*}{0.844} & $752(99.5)$ & $40.44(8.46)$ & \\
\hline Yes & 194 & $49.09(8.93)$ & & $4(0.5)$ & $41.72(10.96)$ & \\
\hline Alcoholism & & & & & & 0.283 \\
\hline No & 455 & $46.67(8.86)$ & \multirow{2}{*}{0.054} & $704(90.5)$ & $42.02(9.13)$ & \\
\hline Yes & 89 & $44.73(7.64)$ & & $74(9.55)$ & $40.96(7.88)$ & \\
\hline Suicide attempt ${ }^{\ddagger}$ & & & & & & 0.001 \\
\hline No & - & - & - & $756(97.2)$ & $38.39(8.42)$ & \\
\hline Yes & - & - & - & $22(2.8)$ & $34.14(10.56)$ & \\
\hline Depression & & & & & & 0.859 \\
\hline No & 456 & $35.82(9.31)$ & \multirow{2}{*}{0.297} & $691(93.0)$ & $36.01(8.41)$ & \\
\hline Yes & 88 & $34.58(9.31)$ & & $52(7.0)$ & $35.78(8.22)$ & \\
\hline
\end{tabular}

*psychosis, alcoholism, and depression of North Korean defectors were diagnosed according to Korean version of Psychiatric Diagnostic Screening Questionnaire, ${ }^{\dagger}$ the data was quoted from Choi's article, ${ }^{17}$ Psychosis, alcoholism, and depression of South Korean were diagnosed according to the Korean version of the WHO-Composite International Diagnostic Interview, ‡existence of attempted suicide were assessed with the question: “Have you attempted suicide?". N: number, SD: standard deviation 
would be lower and that North Korean have a more negative image of attempted suicide than citizens of other countries. ${ }^{20}$ On the other hand, in 2011, the suicide rate in South Korea was very high at 31.7 per 100,000 of the population, ${ }^{24}$ which would a suggest lower perceived stigma for suicide. Furthermore, experiences of defection might have diminished stigma of attempted suicide. For example, North Korean defectors consider escape as a suicide-like behavior due to the threat to life involved, and usually prepare themselves to commit suicide in of capture.

In this study, North Korean defectors had lower perceived stigma for depression than South Koreans. Depressive or anxiety symptoms are usually diagnosed as neurasthenia, cardiac neurosis, or autonomic dysfunction and treated by internal medicine doctors or neurologists. ${ }^{20}$ Because North Koreans lack any concept of depression, it was not surprising they exhibited little stigma for depression.

It was assumed that the subjects of North Korean defectors were likely to have the highest perceived stigma for psychosis followed by alcoholism, suicidal attempt, and depression. Their mean PDD score of alcoholism, however, was higher than that of psychosis among the South Koreans. ${ }^{17}$ As we mentioned previously, North Koreans have a much more negative image of psychosis than other mental illnesses. ${ }^{20}$

Regarding sociodemographic variables, the North Korean defectors who were married or previously married had higher perceived stigmas for psychosis, alcoholism, and depression than those who had never been married. Previous studies have also reported that the never married exhibit lower stigma for mental illness than the married. ${ }^{25,26}$ Other studies have reported that respondents with children show a more negative attitude toward mental illness patients because of concerns about child safety. ${ }^{26-28}$ Thus, the higher perceived stigmas of married or previously married North Korean defectors could be partially explained by these concerns.

In the current study, age was not found to be associated with higher perceived stigmas in North Korean defectors. Prior studies have reported that younger subjects better accept mental illness. ${ }^{17,29}$ This difference could be a unique characteristic of North Korean defectors, who are used to a closed social system, have a powerful negative image of mental illness, and no concept of depression.

North Korean defectors that had spent more than one year in transit to South Korea were found to have lower perceived stigmas for psychosis and alcoholism. Thus their experiences in transit may have reduced these stigmas. On the other hand, because North Korean defectors had relatively lower stigmas for attempted suicide and depression, these stigmas were not changed by time in transit.

North Korean defectors with experience of compulsory re- patriation to North Korea or with more than one family member in North Korea had higher stigma for depression. Compulsory repatriation and the existence of a family member in North Korea undoubtedly create stress, although it is not clear how this affects stigma for depression. It is evident that the effects of compulsory repatriation and of having a family member in North Korea need more intensive study.

Despite the higher prevalence of mental illness in North Korean defectors, the presence of mental illness was not found to be associated with stigma regarding types of mental illness. In a previous study, it was reported that the presence of mental illness did not affect stigma for mental illness in South Korea. ${ }^{17}$

The life adjustments made by North Korean defectors in South Korea are clearly related to mental health. ${ }^{30-32}$ Kim et al. ${ }^{6}$ reported that the majority of North Korean defectors have not used psychiatric services due to lack of information, although such aid was desperately needed. The higher perceived stigmas of North Koreans defectors for mental illnesses and an insufficiency of information seem to explain the rare use of psychiatric services. Among South Koreans, the principal barriers to psychiatric service utilization are associated with misconceptions about mental illnesses. ${ }^{7}$ To increase the psychiatric service utilization ratio, psycho-education should be provided, people should be informed about the importance of mental health, and efforts should be made to counter stigmas exhibited by North Korean defectors with respect to mental illness.

This study has several limitations that warrant consideration. First, the North Korean defectors answered all four PDD types, but the South Koreans answered only one. Thus, because defectors answered many more questions, decreased concentration and boredom might have interfered with the process. Second, the North Korean defectors were recruited specifically at a Settlement Support Center established to meet their needs, and thus, had not been exposed to South Korean culture. Therefore, the results could not be applied to the North Korean defectors settled in community of South Korea or general population of North Korea. Our results provide a means of estimating stigmas exhibited by the North Korean population, but we caution against making hasty generalizations. Third, the prevalence of psychosis determined in the present study was too high, presumably because North Korean defectors have persecutory ideas and are still traumatized by experiences of escaping and associated with adapting at the Settlement Support Center. Evidently, the PDSQ was not appropriate for diagnosing psychosis during the early stage of settlement.

In conclusion, we found that North Korean defectors had higher perceived stigmas for psychosis and alcoholism than South Koreans. In addition, we found that marital status is associated with higher perceived stigmas for psychosis, alcohol- 
ism, and depression. Further studies are needed to determine the effect of psycho-education on the stigmas of North Korean defectors and to document serial changes in stigmas for mental illnesses associated with the receipt of education at the Settlement Support Center for North Korean defectors.

\section{REFERENCES}

1. Number of the North Korean defectors in South Korea until 2013-Ministry of Unification. Available at: http://www.unikorea.go.kr/index.do? menuCd=DOM_000000105006006000. Accessed January 15, 2013.

2. Yoon IJ. Social adjustments of North Korean migrants and measures to facilitate their resettlement. J Asiat Studies 2007;50:106-182.

3. Blair RG. Risk factors associated with PTSD and major depression among Cambodian refugees in Utah. Health Soc Work 2000;25:23-30.

4. Strober S. Social work interventions to alleviated Cambodian refugee psychological distress. Int Soc Work 1994;37:23-35.

5. Medcins Sans Frontieres South Korean Departments. The 2005 Annual Report-Mental Health for North Korean Refugee in South Korea; 2005.

6. Kim HH, Lee YJ, Kim HK, Kim JE, Kim SJ, Bae SM, et al. Prevalence and corrleates of psychiatric symptoms in North Korean defectors. Psychiatry Investig 2011;8:179-185.

7. Cho SJ, Lee JY, Hong JP, Lee HB, Cho MJ, Hahm BJ. Mental health service use in a nationwide sample of Korean adults. Soc Psychiatry Psychiatr Epidemiol 2009;44:943-951.

8. Jang YR, Kim GY, Hansen L, Chiriboga DA. Attitudes of older Korean Americans toward mental health services. J Am Geriatr Soc 2007;55: 616-620.

9. Lee KH. A Study on the Stigma about Persons with Mental Disability. Seoul: Ewha Womans University; 2001.

10. Link BG. Understanding labeling effects in the area of mental disorders: an assessment of the effects of expectations of rejection. Am Sociol Rev 1987;52:96-112.

11. Link BG, Cullen FT, Struening EL, Shrout PE, Dohrenwend BP. A modified labeling theory approach to mental disorders: an empirical assessment. Am Sociol Rev 1989;54:400-423.

12. Link B. Mental patient status, work, and income: an examination of the effects of a psychiatric label. Am Sociol Rev 1982;47:202-215.

13. Zimmerman M, Mattia JI. A self-report scale to help make psychiatric diagnoses: the Psychiatric Diagnostic Screening Questionnaire. Arch Gen Psychiatry 2001;58:787-794.

14. Kwak JH, Kim JB, Choi JS, Kim HC, Jung SW, Lee EJ, et al. Study on standardization of Korean version of Psychiatric diagnostic screening questionnaire: the optimal cutoff scores. J Korean Neruopsychiatr Assoc 2012;51:77-84.

15. Link BG, Struening EL, Rahav M, Phelan JC, Nuttbrock L. On stigma and its consequences: evidence from a longitudinal study of men with dual diagnoses of mental illness and substance abuse. J Health Soc Behav 1997;38:177-190.

16. Perlick DA, Rosenheck RA, Clarkin JF, Sirey JA, Salahi J, Struening EL, et al. Stigma as a barrier to recovery: adverse effects of perceived stig- ma on social adaptation of persons diagnosed with bipolar affective disorder. Psychiatr Serv 2001;52:1627-1632.

17. Choi HJ. The impact of the stigma in the mental health service use of the Korean adult population. Graduate School of Inha University Collection of Doctoral dissertations; 2013.

18. Ruan WJ, Goldstein RB, Chou SP, Smith SM, Saha TD, Pickering RP, et al. The alcohol use disorder and associated disabilities interview schedule-IV (AUDADIS-IV): reliability of new psychiatric diagnostic modules and risk factors in a general population sample. Drug Alcohol Depend 2008;92:27-36.

19. Cho MJ, Seong SJ, Park JE, Chung IW, Lee YM, Bae A et al. Prevalence and correlates of DSM-IV Mental Disorders in South Korean Adults: The Korean Epidemiologic Catchment Area Study 2011 (KECA-2011). Psychiatry Investig. In press.

20. Kim SJ, Park YS, Lee HW, Park SM. Current situation of psychiatry in North Korean: from the viewpoint of North Korean Medical Doctors. Korean J Psychosom Med 2012;20:32-39.

21. Cho YA, Jeon WT, Yu JJ, Um JS. Predictors of depression among North Korean defectors: a 3-year Follow-up Study. Korean J Couns Psychother 2005; 17:467-484.

22. Jeon BH, Kim MD, Hong, SC, Kim NR, Lee, CI, Kwak YS, et al. Prevalence and correlates of depressive symptoms among North Korean defectors living in South Korea for more than one year. Psychiatry Investig 2009;6:122-130.

23. Roqnmo K, Torvik FA, Idstad M, Tambs K. More mental health problems after divorce in couples with high pre-divorce alcohol consumption than in other divorced couples: results from the HUNT-study. BMC Public Health 2013;13:852.

24. Suicidal rate in South Korea in 2011-Korea National Statistical Office Available at: http://kostat.go.kr/portal/english/news/1/8/index. board?bmode=read\&aSeq=260590. Accessed January 15, 2013.

25. Sakong JK, Chae JU. A study of attitudes toward the mentally ill in Pohang community. J Korean Neuropsychiatr Assoc 200;40:50-62.

26. Taylor SM, Dear MJ. Scaling community attitudes toward the mentally ill. Schizophr Bull 1981;7:225-240.

27. Wolff G, Pathare S, Craig T, Leff J. Community attitudes to mental illness. Br J Psychiatry 1996;168:183-190.

28. Wolff G, Pathare S, Craig T, Leff J. Community knowledge of mental illness and reaction to mentally ill people. Br J Psychiatry 1996;168: 191-198.

29. Keyes KM, Hatzenbuehler ML, McLauqhlin KA, Link B, Olfson M, Grant BF, et al. Stigma and treatment of alcohol disorders in the United States. Am J Epidemiol 2010;172:1364-1372.

30. Jeon WT. Review of adaptation and mental health of refugees and perspectives and counterplots in Korean reunification process. J Korean Neruopsychiatr Assoc 1997;36:3-18.

31. Roh DK. The Influences of Idifferences on Adjustment and Mental Health in North Korean Refugees. Seoul: Graduate School of ChungAng University Collection of Doctoral dissertations; 2001.

32. Jeon WT, Min SK, Lee MH, Lee ES. Adjustment of North Korean defectors in South Korea. J Korean Neruopsychiatr Assoc 1997;36:145161. 